\title{
Study of the aerodynamic regime of the cooling system of the foundations of buildings on the filling soil in the conditions of the Far North
}

\author{
Victor Ivanov ${ }^{1, *}$, and Anastasiya Ivanova ${ }^{1}$ \\ ${ }^{1}$ North-Eastern Federal University, Institute of Engineering \& Technology, Department "Heat and gas \\ supply and ventilation”, 50, Kylakovskogo str. Yakutsk, 677000, Russia
}

\begin{abstract}
During construction in the Far North, due to the preservation of permafrost soils, the buildings are arranged on piles and foundations on the bedding soil. In the foundations of buildings for a smaller impact on the ground and prevention from defrosting of the soil, air cooling systems with cooling pipes are provided. Seasonal and daily variations in the temperature of the outside air and intensity of solar radiation cause fluctuations in the temperature regime of the upper layers of the soil. As a result of transformation of natural soils into technogenic, its physical properties change significantly when exposed to negative temperatures. Freezing of the soil thawed out over the summer and its further cooling is achieved by passing cold air in the winter through the air channels. The cooling system must provide the position of the upper surface of the frozen soil state under the building, as adopted by the project.

This paper discusses the aerodynamic mode of the air cooling system for foundations on bedding in permafrost soils during the construction of various buildings and structures while preserving the base soils in a frozen state and using natural cold of the outside air, which will improve the reliability of permafrost bases. An engineering method has been developed for calculating the heat fluxes of soil and pipeline laid in thickness. A technique for engineering calculation of change in the thermal regime depending on the parameters of the outside air is given, which will make it possible to usefully use the energy of the cold enclosed in the ground to warm the outside air.
\end{abstract}

\section{Introduction}

The construction and exploitation of various engineering structures, buildings and communications in the conditions of the Far North is complicated by the extremely continental climate and the presence of permafrost soils [1-3]. To preserve permafrost soils, buildings are arranged on piles and foundations on the bedding soil. In the bases of industrial, warehouse buildings and auxiliary facilities cooling pipes are provided to reduce impact on the soil and prevent from the soil defrosting. On the territory of the distribution of permafrost

\footnotetext{
* Corresponding author: tgv-ykt-415@mail.ru
} 
soils (as opposed to that in the Central Russia) the concept of a layer of seasonal thawing is introduced, depending on the parameters of the ambient air during the year.

The extremely continental climate of Yakutia is well manifested in its whole temperature range: low temperatures of winter and high temperatures of summer, as well as large scale of annual and daily amplitudes. The calculated outdoor temperature of the cold five-day week in the populated areas of Yakutia is in the range of tout $=-42 \ldots-60{ }^{\circ} \mathrm{C}$. The absolute amplitudes of air temperature vary in Tiksi from 84.8 degrees to 104 degrees in the city of Verkhoyansk, in the city of Yakutsk, the amplitude is 102 degrees [4].

A sufficiently large amount of energy is spent on heating the air for ventilation systems. This paper discusses a conceptual and methodological approach to creating an integrated system for preservation of frozen soil and preliminary fuel-free heating of air for ventilation systems. Due to the temperature difference between the ground and the outside air during the winter period, the air for the ventilation system, passing through the cooling pipes, by cooling the ground, is heated during its movement.

In [5-7] distributions of isotherms from pipelines in the ground with hot coolant (heat networks) are considered, in a similar way it is possible to construct a scheme of distribution of isotherms and directions of heat flows from cooling pipelines in the winter period (Fig. 1).

Seasonal and daily variations in temperature of the outside air and intensity of solar radiation cause fluctuations in the temperature regime of the upper layers of the soil. The depth of penetration of seasonal climatic changes in outdoor air reaches up to 20-25 meters. The change in soil temperatures relative to changes in air temperature is observed with a delay. In summer, the depth of seasonal thawing of soils is 2-2.5 meters in average [8].

The efficiency and reliability of the economic development of territories is based on scientific knowledge of climatic parameters, the properties of soils and the physical and mechanical processes occurring in them. As a result of the transformation of natural soils into technogenic, their physical properties change significantly under the influence of negative temperatures [9-12].

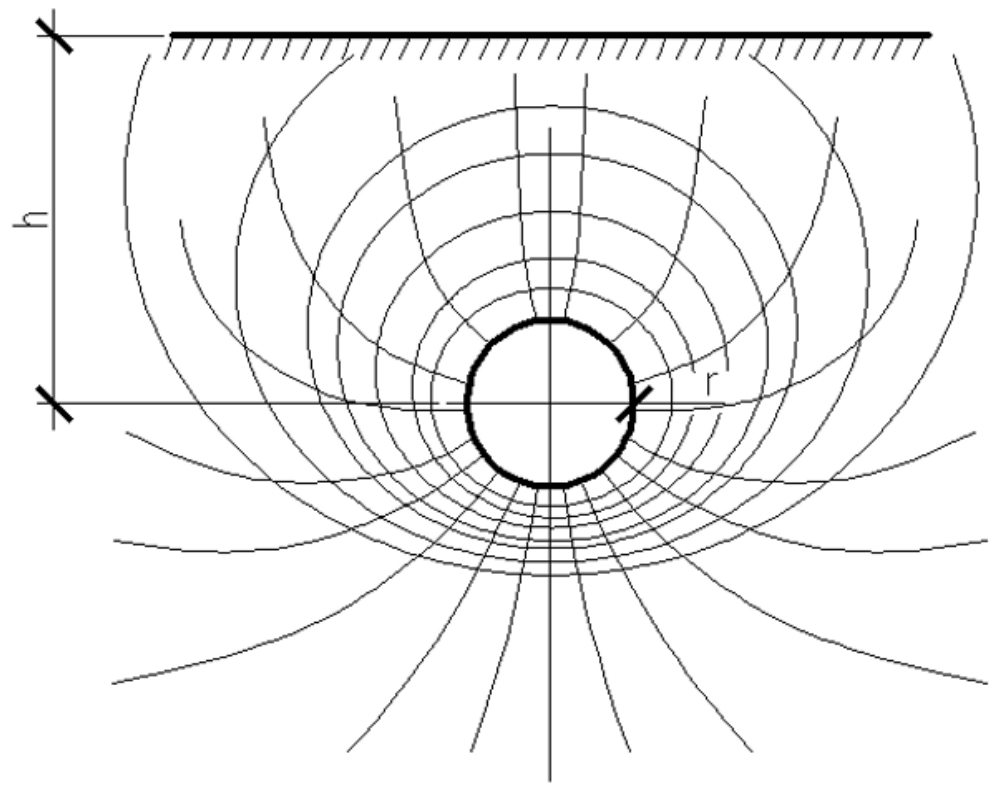

Fig. 1. Heat fluxes in soil

During the man-made impact on permafrost soils, natural heat exchange with the atmosphere is disturbed and one observe change in the soil's thermal regime, the dynamics 
and depth of seasonal and perennial thawing and freezing of the soil, the intensity of the development of cryogenic processes and phenomena negatively affecting engineering and other structures. Consequently, during design, construction and operation of various engineering structures, buildings and communications in the conditions of the Far North, the preservation of frozen rocks, which corresponds to the stability of structures, is a determining factor [13-15]. To ensure the frozen state of the soils, special engineering measures are carried out in the layer (usage of thermal insulation coatings and thermal stabilizers) and on the surface of the soil. Such measures include: the use of sunshades, which reduce solar radiation to the ground surface; snow clearance in winter, which increases the effective radiation from the soil surface; coloring of the soil in a reflective color or the use of natural white gravel, which increases the reflectivity (albedo) of the surface [16-19]. These measures influence the process of heat exchange between the atmosphere and the surface of the earth, which makes it possible to regulate the thermal regime of the soil mass [20-22].

\section{Materials and methods}

This paper considers the aerodynamic mode of the air cooling system for foundations on bedding in permafrost soils during the construction of various buildings and structures while preserving the base soils in a frozen state and using natural cold of the outside air, which will improve the reliability of permafrost bases.

The calculation of the pipeline cooling system consists in determining the system parameters corresponding to the accepted value of the calculated temperature of the permafrost under the building. The calculation is carried out by the method of successive approximations.

The purpose of the study of the aerodynamic regime of the cooling system of buildings in the conditions of the Far North is to determine the optimal radius of the pipes, the depth of the pipes, the spacing of the pipes, the air velocity in the pipes, the difference between the natural aerodynamic pressures at the inlet and outlet of the cooling system.

The engineering design model is a pipeline laid at a depth of 1.6 meters of soil through which the cold outside air flows. The initial data in the thermal calculation are the air temperature at the entrance to the considered object, which receives the heat loss of the soil, the thermal conductivity of the soil, and the ambient temperature cooled by the pipeline. As an example, the temperature of the soil was taken for calculations depending on the depth and the month of the year. Table 1 shows soil temperatures, depending on the depth and the month of the year [7, 23, 24].

In our calculations, heat fluxes and thermal resistance are determined from the surface and through the layer. In this case, the layers are the wall and the array of soil. Since the coefficient of heat transfer from the coolant to the inner surface of the channel is very large, the resistance of the surface of the pipeline and the metal wall in the calculations can be ignored.

Table 1. Soil temperature without the snow covering taking into account (loam and clay)

\begin{tabular}{|c|c|c|c|c|c|c|c|c|c|c|c|c|}
\hline $\begin{array}{c}\text { Depth, } \\
\mathrm{m}\end{array}$ & \multicolumn{10}{|c|}{ Month } \\
\cline { 2 - 15 } & I & II & III & IV & V & VI & VII & VIII & IX & X & XI & XII \\
\hline 0.2 & -31 & -21.7 & -11 & -0.3 & 9.2 & 15.9 & 18.5 & 15.7 & 6 & -11.9 & -33.1 & -33.1 \\
\hline 0.4 & -26.9 & -22.4 & -15.1 & -6.5 & 2 & 9.1 & 13.3 & 13.3 & 7.6 & -5.2 & -21.4 & -21.4 \\
\hline 0.6 & -22.3 & -21.1 & -16.7 & -10.3 & -3.1 & 3.4 & 8.2 & 9.6 & 7.1 & -1.3 & -12.9 & -12.9 \\
\hline 0.8 & -17.9 & -18.8 & -16.5 & -12.1 & -6.5 & -1 & 3.6 & 6 & 5.3 & 0.5 & -7.2 & -7.2 \\
\hline
\end{tabular}




\begin{tabular}{|c|c|c|c|c|c|c|c|c|c|c|c|c|}
\hline 1.2 & -14.2 & -16.2 & -15.4 & -12.6 & -8.6 & -4.2 & -0.2 & 2.5 & 3.1 & 0.8 & -3.7 & -3.7 \\
\hline 1.6 & -11.1 & -13.7 & -13.9 & -12.3 & -9.6 & -6.3 & -3.1 & -0.5 & 0.6 & 0.3 & -1.9 & -1.9 \\
\hline 2.4 & -6.8 & -11.4 & -12.1 & -11.5 & -9.9 & -7.6 & -5.2 & -3 & -1.4 & -0.8 & -1.3 & -1.3 \\
\hline 3.2 & -7.2 & -9.5 & -10.5 & -10.5 & -9.7 & -8.3 & -6.5 & -4.8 & -3.2 & -2 & -1.5 & -1.5 \\
\hline
\end{tabular}

When laying the pipeline in the ground, it represents a certain thermal resistance. Concentrated linear heat sources act in the massif of unlimited space of soil. According to the second law of thermodynamics, the most heated body gives its thermal energy to the colder one. In this case, the cold air, passing through the pipeline, will receive thermal energy from the soil, thereby cooling it to an average negative temperature $[6,7,25,26]$. Thus, the pipeline, laid in the thickness of the soil, will not adversely affect the thermal regime of the soil. The air, passing through the pipeline, will warm up from temperature t1 to temperature $\mathrm{t} 2$, which is the purpose of determining in this work.

Concentrated linear positive and negative heat sources are active in the soil mass. Positive heat sources are denoted as $+\mathrm{Q}$, negative heat sinks are $-\mathrm{Q}$.

The thermal resistance of the soil is determined according to the simplified Forchheimer formula:

$$
R_{\text {soil }}=\frac{1}{2 \pi \lambda_{\text {soil }}} \cdot \ln \frac{4 h}{d}
$$

where $\lambda_{\text {soil }}$ is soil thermal conductivity, $\mathrm{W} /\left(\mathrm{m} \cdot{ }^{\circ} \mathrm{C}\right) ; \mathrm{h}$ is depth of pipeline laying from the earth surface to its axis, $\mathrm{m}$; $\mathrm{d}$ is the pipeline diameter, $\mathrm{m}$

Figure 2 presents the computational model for calculation the thermal mode of the soil.

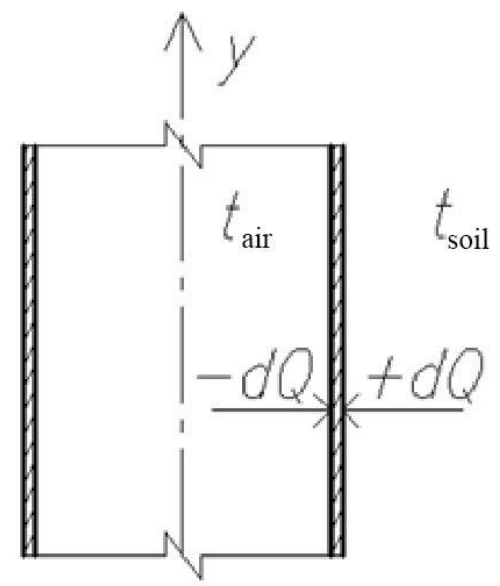

Fig. 2. The computational model

Basing on the well-known expressions, the heat balance is described by the following formulae (taking into account the admitted simplifications):

$$
\left\{\begin{array}{l}
-d Q_{\text {air }}=L_{\text {air }} \rho_{\text {air }} c_{\text {air }} d t, \\
d Q_{\text {soil }}=k_{\text {soil }} \pi D\left(t_{\text {soil }}-t_{\text {air }}\right) d y .
\end{array}\right.
$$

where $\mathrm{dQ}_{\text {air }}$ is deviation of the negative heat sink, $\mathrm{W}$; $\mathrm{dQ}_{\text {soil }}$ is deviation of the heat flux from the heat source, W; $\mathrm{L}$ is air flow capacity, $\mathrm{m}^{3} / \mathrm{h}$; $\mathrm{c}_{\text {air }}$, $\rho_{\text {air }}$ is thermal capacity and density of air, respectively, $\mathrm{kJ} /(\mathrm{kg} \cdot \mathrm{K})$; $\mathrm{k}_{\text {soil }}$ is linear coefficient of heat transfer from soil to air, $\mathrm{W} /(\mathrm{m} \cdot \mathrm{K}) ; \mathrm{t}_{\text {soil }}, \mathrm{t}_{\text {air }}$ is soil and air temperatures, respectively, ${ }^{\circ} \mathrm{C}$. 
Figure 3 shows a plot of heat fluxes between the air flowing in the pipeline and its surrounding soil.

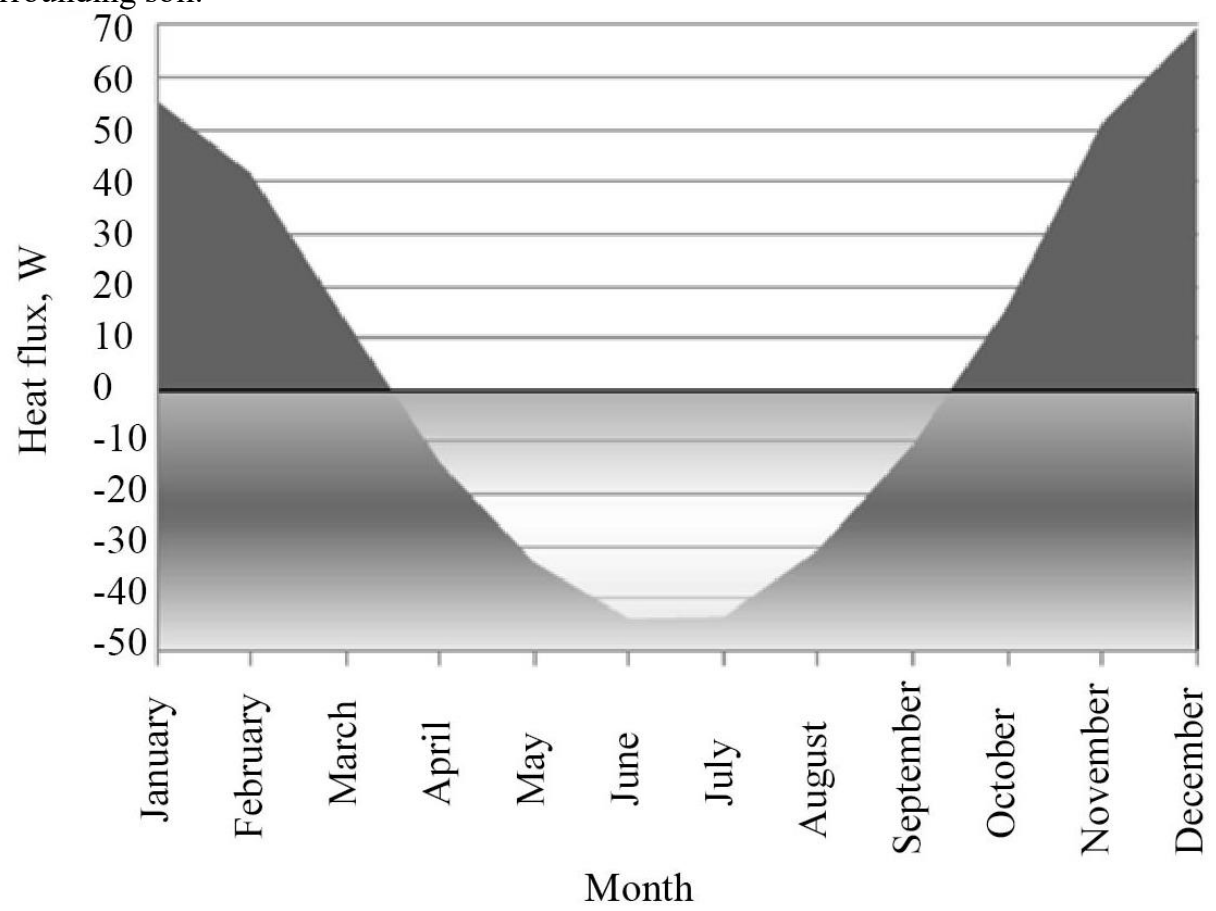

Fig. 3. Heat fluxes from soil to air

\section{Results and Discussion}

As a result of the analysis, we calculated the arranged gravitational pressure of the cooling medium in the design scheme, which allows us to select systems for operation in the natural and mechanical mode. Dependencies for setting the operating mode, starting and stopping periods of the cooling system were determined. The schemes of the engineering solution of the pipeline system and the injection unit are given, taking into account the work in conditions of extremely low outdoor temperatures.

The plot shows that negative values of heat flow determine the start of heating and stopping the period of cooling the soil. According to the obtained values, we determine the operational period of the useful soil cooling and heating of the outside air flowing in the pipeline.

After a series of transformations of formula (2), we obtain:

$$
t_{\text {air }}{ }^{\prime \prime}=t_{\text {soil }}-\left(t_{\text {soil }}-t_{\text {air }}{ }^{\prime}\right) \cdot e^{-\frac{k_{\text {soil }} \pi D y}{L_{\text {air }} \rho_{\text {air }} c_{\text {air }}}}
$$

This equation allows one to calculate the air temperature after passing through the soil thickness in any section of the pipeline, depending on its length.

In the conditions of the Far North, significant complications are found in engineering systems associated with processing and the need to heat the supplied air. The outside air that comes in is directly related to the considerable costs of thermal energy for heating to the required temperatures. On the basis of operational, field data and experimental experiments it was determined that, with a decrease in the outdoor temperature to $-40^{\circ} \mathrm{C}$, the probability of emergency stops and the failure of engineering equipment of buildings increases. When 
the outdoor air temperature reaches $-35{ }^{\circ} \mathrm{C}$ and higher, the efficiency and operability of the systems and related installations increase. Increasing the temperature of the outside air during the operational moments of the heating period in the conditions of the Far North by the fuelfree method of the order of $5-10{ }^{\circ} \mathrm{C}$ significantly saves the cost of thermal energy, increases the reliability and efficiency of operation of systems and devices.

Figure 4 shows the change in outdoor temperature as a function of change in outdoor temperature and the length of the pipeline. As an example we consider a steel pipe with a diameter of $159 \times 4.5$.

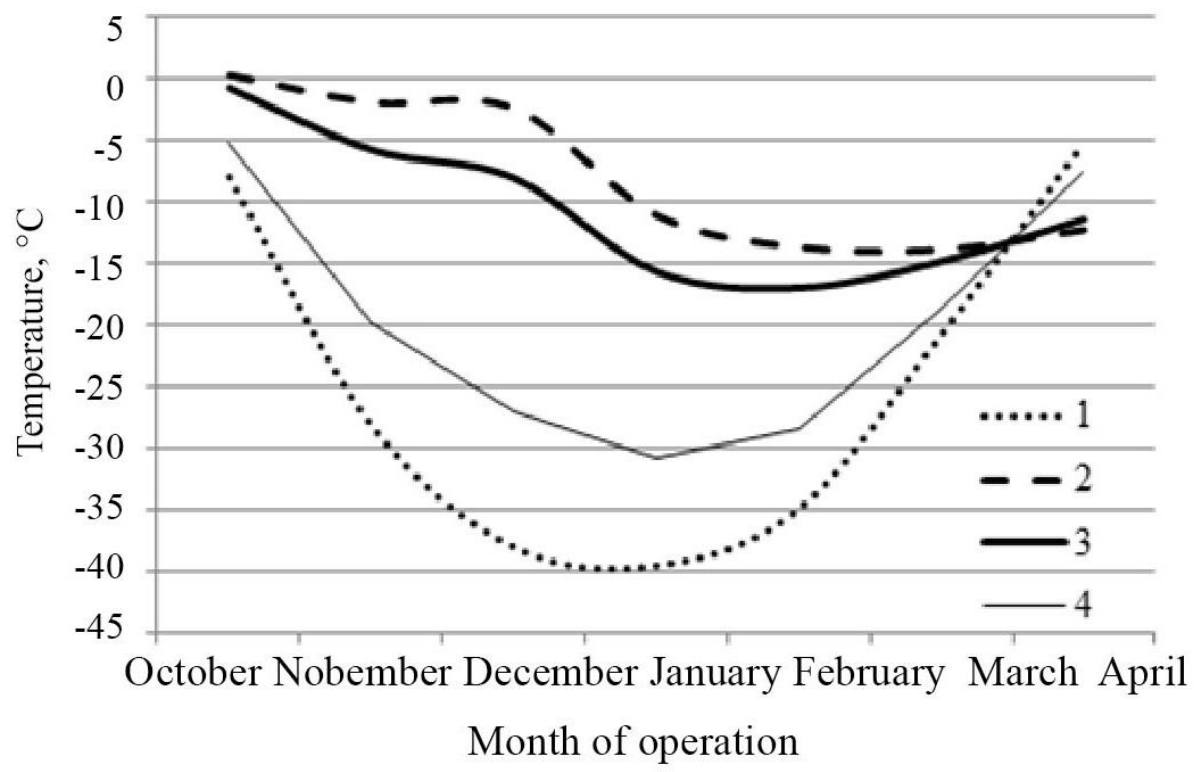

Fig. 4. Temperature distribution during the operational months: 1 - outdoor temperature, 2 - soil temperature, 3 - air temperature at $1=100 \mathrm{~m}, 4$ - air temperature at $1=10 \mathrm{~m}$

The graph clearly shows that the cooling system can be started from the beginning of October until mid-March (for a pipeline length of $100 \mathrm{~m}$ ).

\section{Conclusions}

Thus, managing the impact on the thermal regime of the soil, it is possible to change the depth of thawing and maintain a sufficiently low temperature of the soil itself. This event complies with the requirement for the preservation of frozen rocks to ensure the sustainability and operational reliability of engineering systems and structures. Together with the cooling effect, this scheme is used to heat the abnormally low ambient air temperature to the calculated operating temperatures of engineering equipment. Fuel-free air heating will allow one to save the cost of thermal energy for heating up to the design temperatures, it also provides the ability to work under the conditions presented by manufacturers, i.e. in compliance with passport indicators and protection from icing, stopping at peak consumption and emergency situations. It is necessary to take into account the strict range of the period of operation of this scheme, to protect the soil from the influx of thermal energy. The operational period is about 5-6 months, which takes $70 \%$ of the entire heating period of the region. Yakutia is one of the energy-intensive regions, due to the long heating period, which brings about the need to develop and implement energy-saving measures. 
In our calculations, one of the determining parameters is the heat exchange of the outside air with the surface layer of the soil. Heat exchange is significantly influenced by vegetation, snow cover and so on. In accordance with the presented solutions, it is possible to determine the thermal effect and the change in the thermal regime, taking into account various factors.

\section{References}

1. I. Zaychenko, S. Gutman, O. Kalinina, in Advances in Intelligent Systems and Computing (Springer Verlag, 2018) 692, 453-462 (2018)

2. I.M. Zaychenko,O.V. Kalinina,S.S. Gutman, IBIMA, 758-767 (2016)

3. S.S. Gutman,I.M. Zaychenko,E.V. Rytova, IBIMA, 1439-1449 (2017)

4. SP 131.13330.2012 Building climatology. - Moscow: State Committee for Construction of Russia of Federal State Unitary Enterprise, (2012)

5. A.A. Ionin, B. M. Hlybov, V. N. Bratenkov, E.N. Terletskaya. Heat supply. - Moscow: Stroyizdat. (1982)

6. V.M. Efimov, F.E. Popenko, I.I. Rozhin, A.V. Stepanov, Materialy XI Mezhdunarodnogo simpoziuma po problemam inzhenernogo merzlotovedeniya, 238239 (2017)

7. A.V. Stepanov, G.N. Egorova, Materialy XI Mezhdunarodnogo simpoziuma po problemam inzhenernogo merzlotovedeniya, 322-323 (2017)

8. E.K. Dalbaeva, A.V. Stepanov. Izvestiya Samarskogo nauchnogo centra Rossijskoj akademii nauk (2012)

9. A.V. Stepanov. Heat-mass exchange properties of anthropogenic soil cryolithic zone. Novosibirsk: Science, (2011)

10. K.N. Bol'shev, V.A. Ivanov, A.A. Stepanov, A.M. Timofeev, A.B. Eliseev, Materialy II Mezhdunarodnoj nauchno-tekhnicheskoj konferencii «Sovremennye metody i sredstva issledovaniya teplofizicheskih svojstv veshchestv», 90-96, (2012)

11. V.M. Efimov, F.E. Popenko, I.I. Rozhin, A.V. Stepanov. Geotekhnika 4, 16-23 (2016)

12. A.M. Timofeev, N.A. Protod'yakonova, A.V. Kolmogorov. Trudy II Vserossijskoj nauchno-prakticheskoj konferencii, posvyashchennoj 80-letiyu d.t.n., professora A.P. Ammosova. FGBUN "Institut fiziko-tekhnicheskih problem Severa im. V.P. Larionova SO RAN",384-389 (2017)

13. G. M. Feldman. Methods of calculation of temperature condition of frozen soil. Moscow: Science, (1973)

14. D.A. Krylov, A.A. Fedotov. Bulletin of MSTU named Bauman 3, 106-116 (2013)

15. A.V. Malyshev, A.M. Timofeev, N.A. Protod'yakonova. Trudy VIII Evrazijskogo simpoziuma po problemam prochnosti materialov i mashin dlya regionov holodnogo klimata EURASTRENCOLD-2018, 345-356 (2018)

16. Qin Yinghong, Tan Kanghao, Liang Jia. Cold Regions Science and Technology 120, $148-160,(2015)$

17. CAN/CSA-S500-14 Thermosyphon foundations for buildings in permafrost regions. Canada: National Standart of Canada, CSA Group, (2014)

18. T. Bray Matthew, Cold Regions Science and Technology 79, 43-52, (2012)

19. M.H. JAHANGIR, Journal of Thermal Science and Technology 10, 1 (2015)

20. J.P. Zarling, A.W. Breley. Thaw stabilization of roadway embankments constructed over permafrost. - Alaska DOT\&PF Report No FHWA-AK-RD-87-20, (1986)

21. Wenjie Feng, Zhi Wen, Zhizhong Sun, Junjie Wu. Proceeding of the Eighth International Symposium on Permafrostl Engineering, 148-160 (2009)

22. V.G. Kondratyev, A.G. Perekupka, S.S. Primakov, A.S. Petrova, Oil Industry 10, $122-$ 125 (2012)

23. M.K. Gavrilova. Climate of the Central Yakutia, 119 (1973) 
24. V.T. Balobayev, Yu.B. Skachkov, N.I. Shender. Geography and natural resources 2, 5056 (2009)

25. V.V. Chertishev, V.V1 Chertishev. Bulletin of AltSU 1-2, 176-180 (2011)

26. V.A. Tarasov, D.H. Kharlampidi, A.V. Sherstyuk, Eastern-European Journal of Enterprise Technologies 8(53), 34-40 (2011) 